\title{
PUTAFEMINISMO: UM CAMINHO PELO DIREITO DE TODAS AS MULHERES
}

\author{
Juliana Albuquerque Sulz \\ Frederico Assis Cardoso"
}

PRADA, Monique. Putafeminista. São Paulo: Veneta, 2018.

Trabalhadora sexual, ativista pelos direitos das prostitutas e uma das fundadoras da Central Única de Trabalhadoras e Trabalhadores Sexuais (Cuts), no Brasil, Monique Prada tem evidenciado o seu engajamento pelo país e, igualmente, em constante interlocução com as trabalhadoras sexuais de outros países. Putafeminista se opõe tanto ao que se conhece, no plano do senso comum, sobre a prostituição, como aos estereótipos e preconceitos presentes no imaginário social da profissão. O livro apresenta um novo olhar sobre as prostitutas, seus direitos e as escolhas de condução de suas vidas.

A edição conta com o prefácio da brasileira Amara Moira, travesti e ativista militante da causa LGBTQ+, doutora em teoria e história literária pelo Instituto de Estudos da Linguagem da Universidade Estadual de Campinas (IEL/Unicamp), também escritora, e colunista do suporte jornalístico independente Mídia Ninja. O prefácio traz exemplos triviais de como a palavra "puta” está presente na sociedade, sempre relacionada a tudo que existe de ruim e violento. E é exatamente a partir dessa reflexão sobre o uso da expressão, que Monique Prada revela as dificuldades de construir uma luta pelos direitos das trabalhadoras sexuais. O significante do termo pode causar estranheza e repulsa em diferentes segmentos sociais, sobretudo quando se considera o momento político pós-golpe que reacendeu, no Brasil, a chama do conservadorismo. Já a apresentação do livro é da professora Adriana Piscitelli, pesquisadora doutora do departamento de Antropologia Social e do curso de doutorado em Ciências Sociais da Unicamp, integrante do Núcleo de Estudos de Gênero Pagu, vinculado à mesma Universidade.

Na obra, Monique Prada manifesta a ressignificação do trabalho sexual e, ao mesmo tempo, da militância feminista ao revelar os embates de ordens teóricas e práticas travados dentro dos movimentos de mulheres, em torno da luta pela legitimação do trabalho sexual que ainda produz divisões de opiniões entre algumas feministas. Talvez seja possível afirmar que Monique escolha como interlocutor oculto o movimento feminista conhecido como Radfem.

I Universidade Federal de Minas Gerais (UFMG), Belo Horizonte (MG), Brasil; https://orcid.org/0000-0001-6371-4981; julianaasulz@gmail.com

II Universidade Federal de Minas Gerais (UFMG), Belo Horizonte (MG), Brasil; https://orcid.org/0000-0003-2704-3652; fredasc.ufmg@gmail.com 
Radfem é uma expressão utilizada pela autora para denominar um grupo de mulheres dentro do movimento feminista reconhecidas, e autorreconhecidas, como "radicais"; as radicais feministas. O feminismo radical parte de uma perspectiva interna do próprio movimento feminista e seria fruto da chamada "segunda onda do feminismo" (datada aproximadamente do início dos anos 1960 ao final da década de 1990), que pautaria como agenda o combate à supremacia masculina. Tal tipo de feminismo estaria engajado na tentativa da eliminação dos privilégios econômicos e sociais do patriarcado.

Em uma arena de conflito, em disputa de narrativas, posições e representações, as feministas radicais travariam lutas contra o trabalho sexual, apresentando argumentos assentados na "exploração do corpo", na "objetificação da mulher" e na "manutenção dos interesses do patriarcado", entre outros, para justificar sua oposição ao entendimento da prostituição como uma forma reconhecida de trabalho. Assim, para as radfem, o trabalho sexual não seria possível sem que ele produzisse marcas de violência e exploração contra as mulheres. Talvez esse seja o principal ponto de conflito entre as putasfeministas e as radfem.

Esse feminismo radical consideraria ser possível resgatar as trabalhadoras sexuais, emancipando as mulheres de um tipo de opressão, ainda que desconsiderando suas livres escolhas e consentimentos na maneira como as prostitutas lidam com seu corpo e sua sexualidade. O livro de Monique ganha potencialidade de análise política ao destacar que, muitas vezes, a prostituição é tema de pauta do movimento feminista sem que as próprias mulheres prostitutas sejam ouvidas. Assim, o discurso salvacionista, muito reproduzido pelas instituições religiosas e esfera política conservadora, que precisaria ser desconstruído, continuaria a circular e a ser fortalecido dentro do próprio movimento feminista. Isso significa que, se, por um lado, não se pode negligenciar os casos de violência, abuso ou tráfico de mulheres, por outro, precisamos ouvir o que as prostitutas têm a nos dizer de suas escolhas e suas histórias. E esta talvez seja a grande contribuição de Putafeminista.

O livro evidencia a importância de ler uma autora prostituta, sem desmerecer os estudos científicos que vêm sendo produzidos em diversas áreas do conhecimento, atentando-se para uma obra feita por quem, durante muito tempo, fora apenas objeto de pesquisas. A narrativa experiencial de Monique Prada expõe os interesses e conflitos que movimentam os feminismos contemporâneos que podem reforçar os estigmas sobre as prostitutas e enfraquecer a luta pela liberdade da mulher sobre seu próprio corpo.

Monique ressalta a grande contribuição das redes sociais para dar espaço e potencializar as narrativas das prostitutas. No entanto, a autora aponta que as discussões políticas em torno da luta pelos direitos dessas mulheres geram, a quem defende a regulamentação da prostituição, terríveis ataques e críticas. As feministas conservadoras acusam as pessoas solidárias às causas das trabalhadoras sexuais de serem coniventes com a cultura do estupro e fomentarem, ainda, a prática do tráfico de mulheres. Essas acusações, segundo a autora, tentam deslegitimar as prostitutas feministas. Monique Prada assinala, a partir desses 
conflitos, a necessidade de compreender melhor o mundo da prostituição, que é visto pela sociedade como um mundo paralelo em que as trabalhadoras sexuais não se mobilizam, não se informam e não lutam. Nasce, então, o putafeminismo com a pretensão de pensar e repensar os feminismos já existentes, sobretudo aqueles que não contemplam as trabalhadoras sexuais. A ideia norteadora desse movimento seria de que as prostitutas teriam o direito de serem feministas e, ao mesmo tempo, fortalecerem a luta pelos seus direitos. Para além disso, as putasfeministas desejam reconfigurar a estrutura da prostituição para combater as opressões culturais, econômicas, políticas e sociais que pesam sobre a profissão e produzem visões distorcidas, estereotipadas e preconceituosas das trabalhadoras sexuais.

Após a leitura, fica evidente que Monique Prada conseguiu de maneira sutil e perspicaz apontar as amarras da sociedade imersas em relações hipócritas. No momento em que a autora apresenta o perfil da maioria de seus clientes, sua intenção não é trazer ao leitor uma dose de mistério ou sanar curiosidades sobre sua vida sexual, mas sim levar a uma reflexão crítica sobre os consumidores da prostituição. As mesmas pessoas que fazem uso da prostituição, na condição de clientes, nos dias de hoje se revestem de um discurso sem representação no plano real em prol de um modelo antigo, restrito e conservador de família tradicional, que só serve para deslegitimar a luta pelos direitos das trabalhadoras sexuais.

Assim, a autora nos convida a refletir que, na verdade, a prostituição é uma instituição tão antiga e sólida quanto o matrimônio. Considerando que os prostíbulos são frequentados majoritariamente por homens "pais de família", a sociedade patriarcal reforça e naturaliza a relação do homem capaz de pagar por sexo. A heteronormatividade da masculinidade hegemônica produziria uma identidade em que a movimentação de homens em busca de sexo pago poderia ser compreendida como "natural", algo pertencente às normas sociais dos homens. Paradoxalmente, esse mesmo tipo de masculinidade representaria as trabalhadoras sexuais como mulheres que prestam um determinado de tipo de serviço, tido como inferior em uma escala social de ocupações. Em última análise, seria como se a prostituição só existisse por conta delas e não porque há quem as procure.

A autora considera que o movimento feminista tem chegado, de fato, aos puteiros e que isso não deveria incomodar algumas militantes. Assim como qualquer profissão, as trabalhadoras sexuais têm o direito de exigir respeito, sexo consentido e justa remuneração. É por esse feminismo que as prostitutas estariam lutando, de todas e para todas as mulheres. O desconforto que o livro pode trazer para as radfem encontra-se justamente na quebra da concepção de que uma prostituta não poderia falar por si mesma, de que não poderia estar ciente de suas escolhas em relação ao seu próprio corpo e à sua sexualidade. E a crítica mais contundente presente no putafeminismo é a de que, durante muito tempo, se ouviu falar sobre as putas, ainda que tenham sido pouco representativas as oportunidades em que as trabalhadoras sexuais foram ouvidas.

O movimento das putasfeministas nos coloca a necessidade de entender a diferença entre trabalho, crime e exploração. Para construir políticas públicas que 
garantam direitos a essas trabalhadoras, é imprescindível estabelecer o que seria exploração laboral e exploração sexual. Na ordem do capital, a exploração laboral estaria presente em todas as relações de trabalho. $\mathrm{O}$ empoderamento exigido pelas feministas, e até certo ponto adotado por algumas trabalhadoras sexuais, nos parece quase impossível diante da realidade exposta por Monique: a de que nenhum trabalho exercido em nossa sociedade pode ser totalmente empoderado, entendido como trabalho totalmente livre, sobretudo quando nos referimos ao trabalho de mulheres com baixa escolaridade e oriundas ou pertencentes a frações mais vulneráveis da pirâmide social. Isso significa que os questionamentos aquecidos no interior dos movimentos feministas conservadores sobre empoderamento de mulheres são direcionados às prostitutas em tom de cobrança ou crítica e pouco se movimentou essa pauta para outras profissões.

A sociedade parece não se importar com as explorações de outros trabalhos precários, como por exemplo o de empregadas domésticas, função exercida ainda em muitos lares brasileiros e cujos direitos sociais representam conquistas recentes não totalmente consolidadas. Infelizmente o Brasil tem conhecido, recentemente, uma crescente onda de discursos e narrativas, muitas vezes, produzida por políticos extremamente conservadores e por integrantes de religiões reacionárias, de cunho notadamente moralista; discursos inclinados para o retrocesso na forma de compreender as relações de gênero, de corpo e de sexualidade. Para o grupo de retrógrados políticos e líderes religiosos, pouco importa de fato a exploração do trabalho de mulheres em todas as profissões, como mostram os escândalos que denunciam os trabalhos análogos à escravidão, por exemplo. Na linha de frente desse grupo estão os ataques às trabalhadoras sexuais e à sua organização por direitos e políticas públicas capazes de lhes atender. Ataques ao que essas mulheres significam, mulheres interessadas no combate à violência, atuantes na prevenção de doenças sexualmente transmissíveis e no acolhimento de pessoas em risco de vulnerabilidade social, no ativismo pelo controle do tempo de seu trabalho e por sua justa remuneração. Para além dessas questões, seriam ainda pautas do movimento putafeminismo as questões referentes à previdência social, por exemplo.

De peito aberto, não precisamos falar das putasfeministas, precisamos ouvi-las, lê-las, legitimar e garantir seus direitos enquanto trabalhadoras. A noção salvacionista precisa ser superada. Afinal, por que, ainda hoje, ser prostituta causa tanta revolta na sociedade? A quem interessaria o fim da prostituição? Quais seriam as principais diferenças entre os trabalhos desenvolvidos por mulheres na prostituição e aqueles exercidos por mulheres em profissões socialmente menos valorizadas e de baixa remuneração?

Monique Prada deixa bem evidente em sua obra que um feminismo de todas as mulheres e para todas as mulheres abre caminho e legitima a luta pela regularização da profissão e de todos seus direitos. É claro que existem mulheres exploradas, em situação de violência e risco. Lutar pelos direitos das trabalhadoras sexuais não implica esquecer os casos de opressão, exploração e abuso que as mulheres, sendo putas ou não, sofrem. Monique inaugura um primeiro e 
importante passo ao redirecionar o olhar literário para as trabalhadoras sexuais que precisam de segurança para exercerem sua profissão. Para além das construções religiosas sobre gênero, corpo e sexualidade, é preciso, assim como na questão do aborto, deixar que as mulheres sejam donas de seus corpos, de suas sexualidades, de suas vidas e suas histórias, de seus sonhos e de seus desejos. A leitura analítica de Monique sobre a prostituição e o feminismo é bastante produtiva, e até mesmo otimista, podendo interessar leitores e leitoras de diversas áreas, bem como o público leigo em geral, resumindo a premissa de que haveria uma enorme diferença entre obras que registram uma história sobre as mulheres prostitutas e uma história de mulheres prostitutas por elas narrada.

\section{REFERÊNCIAS}

PRADA, Monique. Putafeminista. São Paulo: Veneta, 2018.

NOTA: A produção desta resenha foi realizada efetivamente pelos dois autores após reescrita de duas versões antes da submissão.

\section{COMO CITAR ESTA RESENHA}

SULZ, Juliana Albuquerque; CARDOSO, Frederico Assis. Putafeminismo: um caminho pelo direito de todas as mulheres. Cadernos de Pesquisa, São Paulo, v. 49, n. 172, p. 344-348, abr./jun. 2019. [Seção] Resenhas. Resenha da obra de: PRADA, Monique. Putafeminista. São Paulo: Veneta, 2018. https://doi.org/10.1590/198053146283 
